\section{Depletion of ozone layer drives competitors to cooperate}

\section{Washington}

INTERNATIONAL pressure for massive cuts in the production of chlorofluorocarbons (CFCs) that may damage the Earth's ozone layer is having its effect on the big chemical manufacturing companies. In the wake of the Montreal agreement, signed in September 1987, to halve the consumption of halogenated chlorofluorocarbons, thirteen competing companies from seven nations are joining together to speed the testing of alternative, less-damaging compounds.

It is the first time that so many of the world's giant chemical manufacturers companies such as Du Pont (United States), ICI (United Kingdom), Hoechst (West Germany), and Asahi Glass (Japan) - have agreed to cooperate in an international project. They will not, however, be sharing all their trade secrets. Each company is competing to develop new alternatives to CFCs currently in use as refrigerants, polyurethane-blowing agents, solvents and propellants. But they will cooperate to test the toxicity of two agents - HFC-123 and HFC-134a already widely canvassed as alternatives. Both agents are much less stable than existing CFCs and are much less likely to disrupt the ozone layer. Toxicity testing is

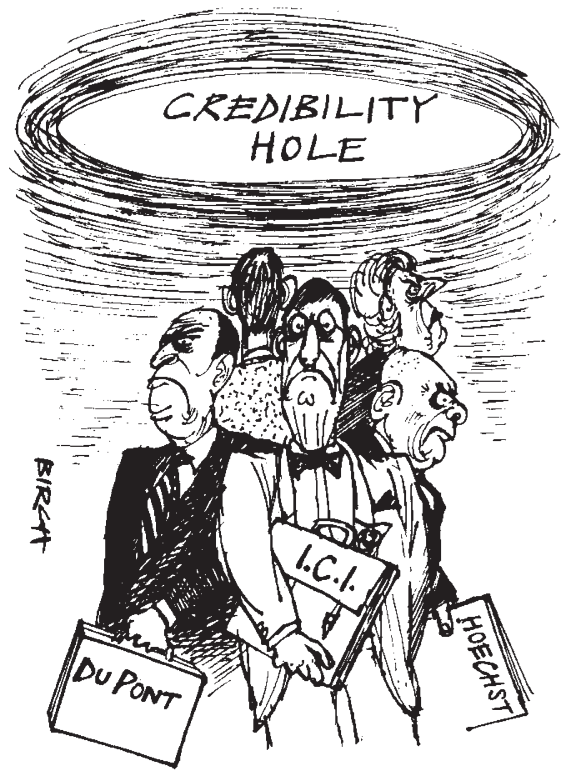

the most time-consuming job left to be done before they can be routinely used. By pooling their knowledge and by sharing expenses, the thirteen companies hope that the job can be completed as quickly as possible. Even so, a final toxicity report is not expected for 5-7 years.

Alun Anderson

\title{
Early Arctic warming may foil Antarctic expedition
}

\section{London}

AN expedition to the Arctic region has been set up which may shed light on the cause of the ozone destruction in the Antarctic.

A group from West Germany, France and the United States is embarking on a series of atmospheric experiments at Kiruna in northern Sweden. According to Professor Paul Crutzen of the Max Planck Institute for Chemistry, Mainz, the aim of the experiments is to see what is happening to ozone and other constituents such as $\mathrm{ClO}, \mathrm{NO}_{2}, \mathrm{NO}$ and $\mathrm{OClO}$ in the Arctic stratosphere to compare with the results of similar measurements made at the Antarctic over the past couple of years when investigating the 'ozone hole'. Ground-based measurements and balloon and aircraft measurements are planned and the aircraft (supplied by NASA) is equipped with a lidar to give information on the particle composition of polar stratospheric cloud. (Polar stratospheric cloud is thought to play a part in the Antarctic springtime ozone depletion.)

Some scientists have been at Kiruna since before Christmas but one problem facing them is that the winter stratospheric 'sudden warming' is the earliest that has ever been detected.

The stratospheric warming usually does not start before mid-December and the subsequent breakdown of the stratospheric wintertime circulation does not start before the beginning of January. However, this year the warming began at the end of November (about three weeks earlier than usual). This caused an early breakdown of the Arctic polar vortex (which is both looser, warmer and more mobile than the Antarctic vortex).

Fortunately, the cold polar vortex has had time to re-establish itself although until recently the low temperatures associated with the vortex were over the North Pole. But on 18 January temperatures as low as $-70^{\circ} \mathrm{C}$ at the 50 -mbar level were reported over Kiruna. Temperatures at least as low as this, but preferably lower, are needed says Professor Karin Labitzke of Freie University, Berlin. Otherwise, the experimenters will not be able to make the measurements with the Arctic polar vortex that they have planned.

Philippa Lloyd

\section{Remote Soviet observatory is observed}

\section{London}

THE 'mysterious complex' on Mount Sanglok in Tadjikstan, which the Western media have claimed is a military installation, is simply an astrophysical observatory, Pravda has announced. But instead of shrugging off the allegations, Pravda has published a long article on the work of the observatory, including four photographs.

The Mount Sanglok facility, according to Pravda's Tadjikstan correspondent, A. Pokrovskii, is designed for the optical observation of celestial bodies. Although it has only a $1-\mathrm{m}$ telescope, the observatory staff explained that the Tadjik 'astroclimate' - the transparency of the atmosphere and the absence of background illumination - gives almost unparalleled viewing capabilities (some 1,300-1,600 night observation hours a year) and results comparable to those obtained by much larger instruments.

The Sanglok observatory, among other things, monitors artificial Earth satellites and space-probes. Pokrovskii emphasized its observations of the lunar probes Zond-8 and Luna-16 and 17, indicating that the observatory has been operational since the late $1960 \mathrm{~s}$. But according to the published photographs, construction work at the site is still not completed - a powerful indication of the non-military nature of the establishment.

Western suspicions about Sanglok were aroused, Pokrovskii speculates, by satellite photographs from $800 \mathrm{~km}$ of this complex in the remote mountains of Tadjikstan, near the Afghanistan frontier, and linked to the Nurek hydroelectric station some $16 \mathrm{~km}$ away. Political 'clouds', he suggests, led Western commentators to assume that it was a laser installation.

Nevertheless, some questions about Sanglok are unanswered. Pokrovskii reports seeing a number of domes, similar to the observatory's telescope dome nearby, explained only by "another organization has an observatory there". Lasers, too, come into the picture. The tracking of modern geostationary and high-ellipticity satellites, Pokrovskii was told, requires new passive opto-electronic tracking systems. The Soviet Union is therefore developing a system to be installed at Sanglok, which is said to be "roughly similar" to the US Geodes system. There has been some discussion in the West as to whether Geodes conforms to the requirements of the Anti-Ballistic Missile treaty. But, according to Pokrovskii, the experts of both sides see no violation of the treaty from such a system.

Vera Rich 